\title{
Application of wavelets to improvement of defects visibility in active thermography
}

\author{
by M. Kurpiński*, M. Fidali*
}

Silesian Univ. of Technology, 44-100 , 18a Konarskiego Str., Gliwice, Poland, michal.kurpinski@polsl.pl

\begin{abstract}
Detecting defects in adhesively bonded joints using active thermography methods is very promising NDT method. One of the important issue in active thermography is processing of IR image sequence in order to improve defects visibility and detectability. The Wavelet Transform is one of the powerful signal and image processing tool which can be applied to infrared images gathered during active thermography tests. Application of wavelet transform requires to set optimal transform parameters like wavelet type and decomposition level. In the article results of application of wavelet transform to processing of active thermography data were presented. During the research focused on application of wavelets to improve of visibility of defects of adhesively bonded joints.
\end{abstract}

\section{Introduction}

From the car manufacturers point of view it is necessary to provide effective detection of technological flaws of adhesive bonded joints. Anyway, active thermography are rarely applied in testing the bonded structures in automotive industry. The aim of the authors research is to develop an industrial method of quality control of adhesive bonded joints by use active thermography methods. To reach this task, various operations on IR images taken during the active thermography tests are taken into considerations. One of the basic operation is the Fourier Transform. It provides decomposition of the signal by turning it from the time domain to frequency domain. However, it is unable to verify transient signal fluctuation, which could be crucial during analysing of a thermal signal. It is mostly due the harmonic function, to decompose the signal to its frequency components [1-3]. The Wavelet Transform is more reliable because it uses base functions called wavelets to obtain information about signal structure simultaneously in time and frequency (scale) domain $[1,3]$. The main advantage of application of the wavelet analysis is their good sensitivity to unlineraties and discontinuities in the signals. Effective application of wavelet transform requires selection of appropriate base function. It requires preliminary research and could be time consuming. During the research focused on finding appropriate wavelet function which could be useful to improve defect visibility in bonded joints. Besides commonly known and applied wavelet functions as an alternative a Quincunx wavelets were also considered. The Quincunx wavelets were successfully applied to detect and localize defects in composite structures with use of vibration methods [4]. Due to plenty of images gathered during the active thermography test, decided to automatize infrared image processing tasks by application of auto-assessment method based on a Structural SIMilarity method (SSIM). The Structural Similarity is one of the most popular method to compare two images and quantitatively describe their similarity [6].

\section{Active thermography Test setup and parameters}

Infrared images applied during the research were gathered during the active thermography tests performed on laboratory stand. The stand allows testing the specimens with use of both Pulse and Lock-In active thermography methods. The stand consist of the test chamber with specimen holder, two halogen lamps with power $1 \mathrm{~kW}$ each and uncooled infrared camera Infratec VarioCam connected to the PC with installed acquisition and control software. Camera has resolution of $640 \times 480 \mathrm{px}$ and is able to acquire images with frame rate up to $50 \mathrm{fps}$

The tested specimens were $150 \times 75 \mathrm{~mm}$ steel sheets bonded by adhesive to create a sandwich structure. It is a thermosetting, solvent-free, one-component, rubber-based adhesive call TEROSON RB 5194 GB. Shapes and covered area of the adhesive layer were different. For article purposes we decide to analyse infrared images of sample with pattern of adhesives areas presented in Fig. 1. The outside surfaces of steel sheets have been black painted in order to increase its emissivity to 0.92 .

The specimens were tested using pulse thermography. Optimal pulse duration $700 \mathrm{~ms}$ was found during the preliminary research. Infrared images were recorded by the IR camera with maximal frame rate $(50 \mathrm{~Hz})$. The acquisition procedure were performed for two sides of the sample. Exemplary infrared images of the tested sample taken from front and rear side are presented in Fig. 2. In the Fig. 2. also, have shown places where measurement definitions necessary to processing the infrared data were set manually. The definitions are square region of $11 \times 11$ pixels. The measurement definitions $B 1$ and B2 describe areas of the specimens where adhesive layer is not present. We call this area as background. Measurement definitions $A 1$ and A2 concern areas where adhesive layers are present. On the basis of matrix of pixel values inside the measurement definition a median values were calculated. Preliminary investigations have shown that median is more reliable for further data processing than a mean value. Plots showing median values calculated for pixels from $\mathrm{A} 1$ and $\mathrm{A} 2$ and $\mathrm{B} 1$ and $\mathrm{B} 2$ definitions for both sides of the specimens were presented in Fig. 3. 
(a)

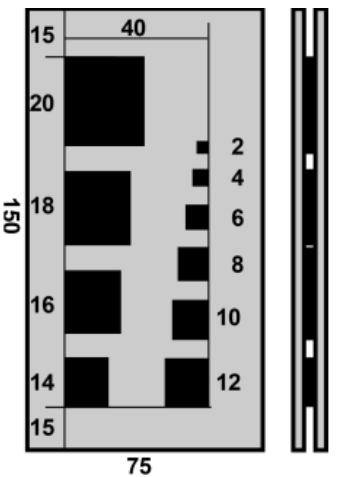

(b)

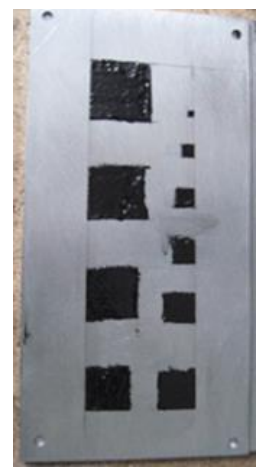

Fig. 1. Experimental sample: specification(a), preparation (b)

(a)

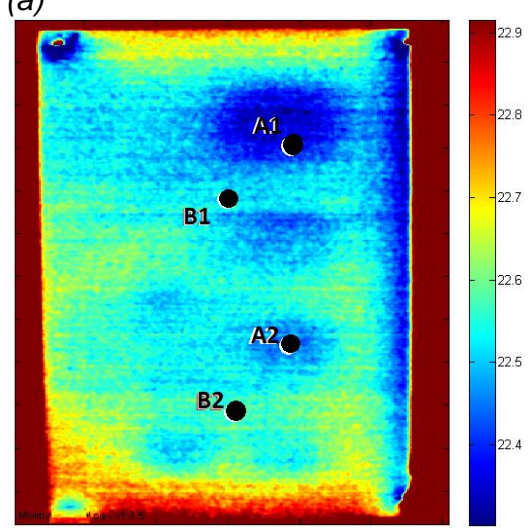

(b)

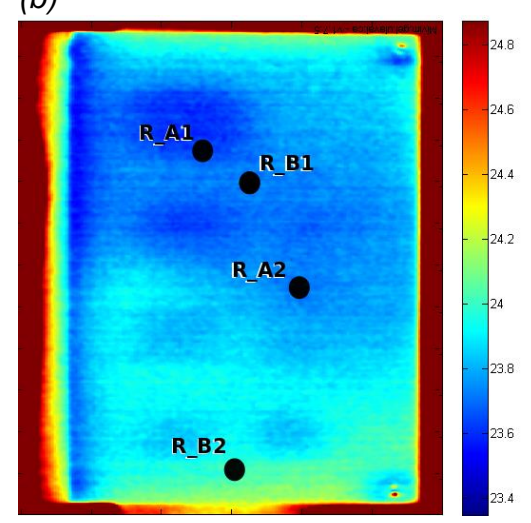

Fig. 2. Points of zones took into consideration (a) front side of the sample, (b) back side of the sample

For purposes of further analysis of infrared data we decide to set zero of time line to point where the heat excitation ends and cooling process begins.
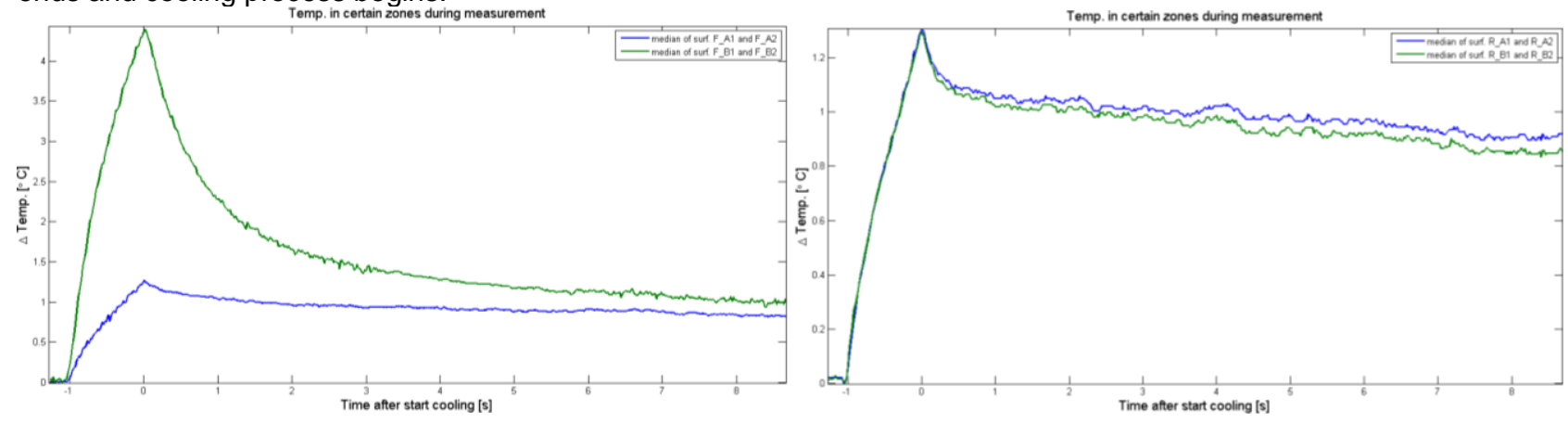

Fig. 3. Acquired test sequence in respect to the adhesive and background sectors visible on Fig.2.

\section{Infrared Data Processing}

Pulse thermography is fast and reliable method however resulted infrared images very often reveal heating ununiformity which can disturb proper detection and localization of structural flaws.

Many publications [9] shows, that PT method combined with good image processing algorithm can increase of defects detectability. One of the most promising method is the 2D Wavelet Transform. There are articles where WT was performed to occur efficient filtration of an NDT IR images [3]. Some sources [1,10] proofs that WT can be applied to find defects in composite structures with thermography methods. In this paper, Authors apply WT to improve defects visibility 
Before application of the WT it was necessary to apply pre-processing operations on the infrared data. In Fig. 4. a simplified diagram of data processing algorithm are presented. The most operation are pre-processing one and consisted on image resizing and pixels value adjusting. First step is selection of Region of Interest (ROI) to reduce size of processed images and increase processing speed. This operation allowed us to exclude from processing more than half of irrelevant pixels of each image of gathered sequence.

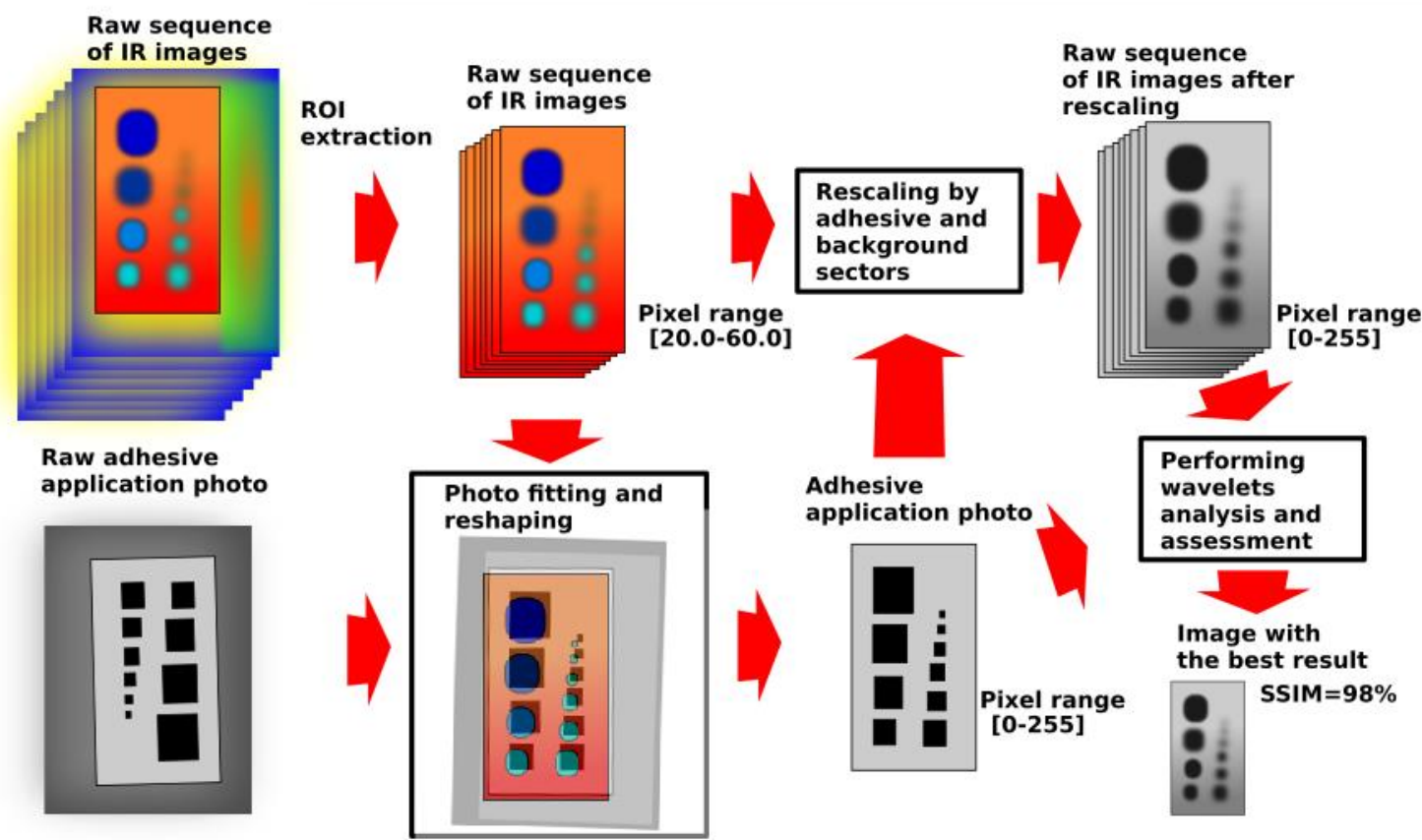

Fig. 4. Overall processing schematic

Simultaneously preparation of reference image presented layout of adhesive layer localisation in specimen was done. We use picture (Fig 1b.) of adhesive layout taken before bonding of steel plates. Using image processing software Gimp the raw picture of adhesive layout was move, rotate, reshape and rescale to fit it to infrared image. During image fitting a blending operation was also used. The results of reference image preparation are shown in Fig. 5.

(a)

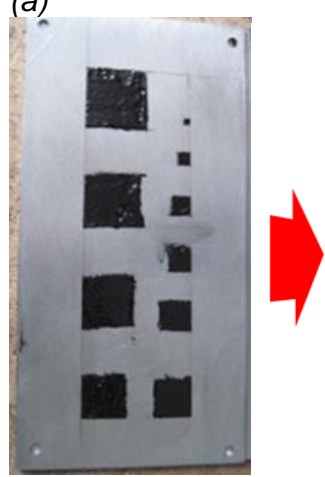

(b)

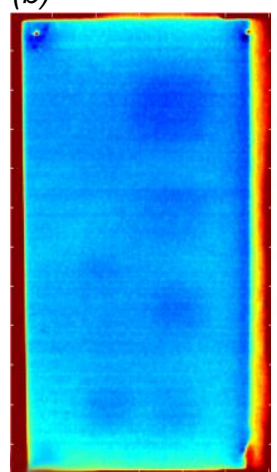

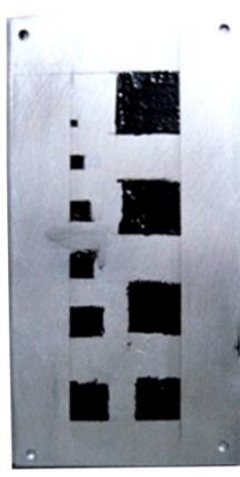

(c)

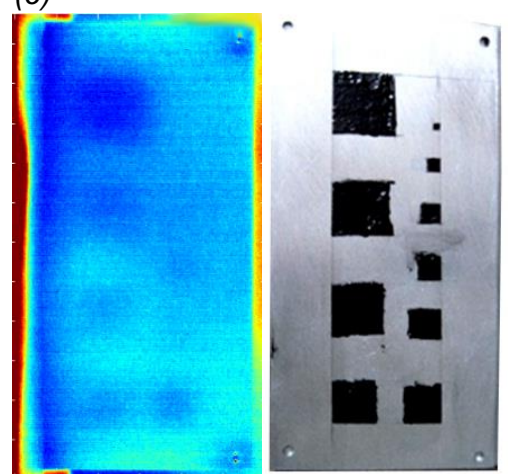

Fig. 5. Photo of the adhesive layout reshaped to fit IR images': (a) front surface (b)back surface

A reference image was used to similarity measurements of processed infrared images. It allowed us find optimal WT parameters. Reference image was also applied to rescale and adjust pixel values of infrared images to grey scale image range of 0-255 values. Conversion of radiometric infrared image pixel values represented by floating point numbers to grey scale image was realized in different way that is commonly implemented in many routines (e.g. Matlab). Conversion was done using linear interpolation based on function $T(R I)$ represented median values of temperatures $T$ in domain of median values of reference image (RI). The median values both of infrared and reference image used for finding linear function parameters were calculated based on pixels of earlier defined regions of measurement definitions. Idea of adjusted of pixel values of infrared and reference images is presented in Fig. 6. 


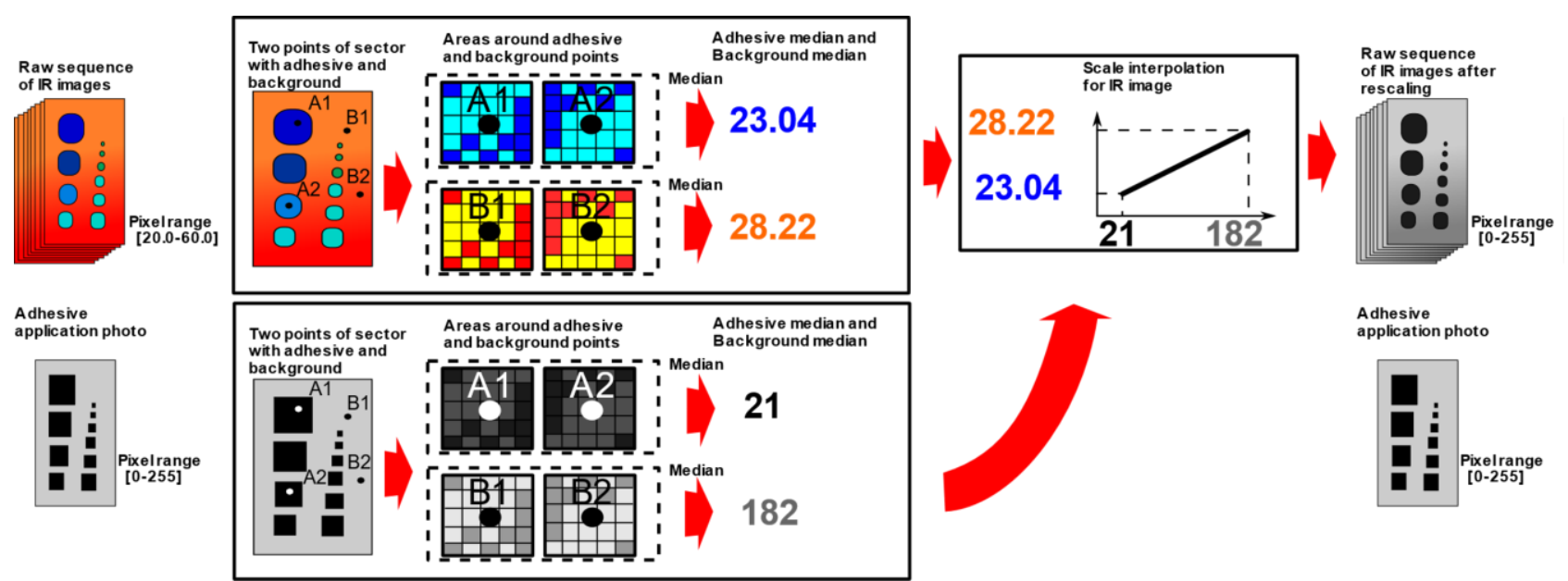

Fig. 6. Schematic diagram of conversion of radiometric IR images to grey scale values range

Pre-processed infrared images were transformed using 2D Wavelets functions implemented in Matlab software. To minimalize computing time transformation were performed using five types of base functions. First four wavelets families are widely used in signal and image processing applications and there were: haar wavelets, discrete meyer wavelets, symlets and daubechies wavelets [9,11]. For symlets and daubechies families used sym1, sym2, sym3 and db2, db3 wavelets respectively. As the fifth base function was quincunx wavelet type. Quincunx wavelets belongs to orthogonal wavelets transform. Anyway, one of the biggest advantage of this method is the finer scale progression than the scheme used in classical DWT mentioned before (a factor $\sqrt{2}$ instead of 2). Moreover, the decomposition with use of quincunx transform results in a single set of approximation coefficients and a single set of detail coefficients.

With use of classical 2D DWT decomposition the results are represented by three matrixes (horizontal, vertical, diagonal) of data on each level of decomposition [7]. A three levels of decomposition were considered. To simplify the analysis of defects localization it was necessary to reduce data. We decide to calculate geometrical mean from those three matrixes

$$
\mathrm{M}(\mathbf{x}, \mathbf{y})=\sqrt{D_{V}(\mathbf{x}, \mathbf{y})+D_{H}(\mathbf{x}, \mathbf{y})+D_{D}(\mathbf{x}, \mathbf{y})}
$$

Where:

$\mathrm{M}(\mathrm{x}, \mathrm{y})$ - result matrix

$\mathrm{DV}, \mathrm{H}, \mathrm{D}(\mathrm{x}, \mathrm{y})$ - three detail matrixes of WT (Vertical, Horizontal, Diagonal)

$x, y-$ position of the pixel

A DWT with use of quincunx wavelet was applied on 17 orders.

Application of DWT causes reduction of resolution in output images. The final step of processing algorithm was fitting resolution of images after DWT to the original one and adjusting of pixels range according to earlier described algorithm (Fig. 6). The whole algorithm of processioning of infrared data with the use of DWT is presented on diagram in Fig. 7.
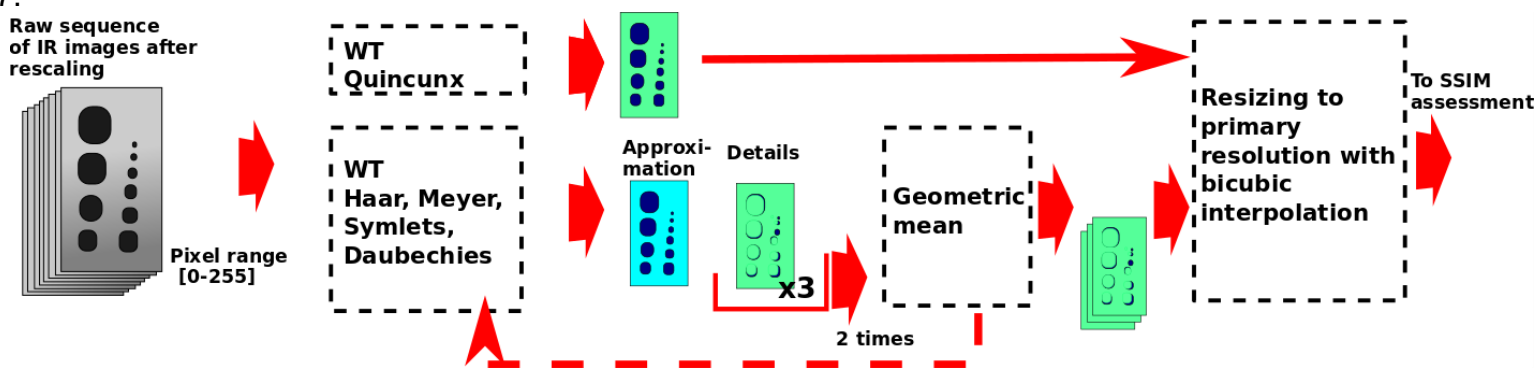

Fig. 7. Schematic of Wavelets Transform image processing sequence

Due to the huge set of images it was necessary to provide automatic image assessing procedure. There are some image quality measures which could be used in this task $[12,13]$. One of the most popular is picture quality estimation method called SSIM. The Structural SIMilarity (SSIM) index is an assessment method of two images comparison. The 
SSIM index should be applied as a quality measure of one of the images compared to the second one. One of the images is threated as reference (perfect quality) to the second image [5]. Equation (2) shows the way of calculation of this measure [6]:

$$
\operatorname{SSIM}(\mathbf{x}, \mathbf{y})=\frac{\left(2 \mu_{x} \mu_{y}+C_{1}\right)\left(2 \sigma_{x y}+C_{2}\right)}{\left(\mu_{x}^{2}+\mu_{y}^{2}+C_{1}\right)\left(\sigma_{x}^{2}+\sigma_{y}^{2}+C_{2}\right)}
$$

Where:

$\mu_{x}, \mu_{y}$ - average value of image $x, y$

$\sigma_{x}{ }^{2}, \sigma_{y}^{2}-$ variance value of image $x, y$

$\sigma_{x y}-$ covariance of $x$ and $y$

$\mathrm{C} 1=\left(\mathrm{k}_{1} \mathrm{~L}\right)^{2}, \mathrm{C} 1=\left(\mathrm{k}_{2} \mathrm{~L}\right)^{2} ; \mathrm{k}_{1}=0.01, \mathrm{k}_{2}=0.03$ in default use, $\mathrm{L}$-dynamic range of the pixel values (for grayscale images $\mathrm{L}=255)$

During the assessment procedure, each image after processing with use of DWT was compared to reference image of adhesive layout. To provide this, both images types have to be in the same scale range.

Application of SSIM measures gave uncertain results. Some of the picture after wavelet transform with low SSIM index presented better visibility of defects than those one with higher SSIM value. Therefore, additionally a visual comparison of processed images was done.

\section{The results}

During the research a sequence of 250 images for both sides of the sample were processed. Considering 5 families of wavelets finally a set of 20000 images were assessed. The only way to assess it effectively, it was necessary to calculate SSIM index for every configuration and find maximum value. In the Table 1. a selected assessment results for 80 images were presented. Visual inspection of the images appearance provides Authors to the statement, that figures with SSIM value below $50 \%$ of similarity are useless. Visual inspection showed us that the best effect visibility provides images obtained after WT with use of quincunx wavelets. Selected images indicated in the table by bold font were shown in Fig. 8 and Fig. 9.

Table 1. Maximal SSIM values of selected images by each order (images of bolded SSIM values are presented on Fig. 8 and 9.

\begin{tabular}{|c|c|c|c|c|c|c|c|c|c|c|c|}
\hline \multirow{2}{*}{\multicolumn{2}{|c|}{$\begin{array}{c}\text { WT type } \\
\text { Order }\end{array}$}} & \multicolumn{10}{|c|}{ Quincunx } \\
\hline & & 1 & 2 & 3 & 4 & 5 & 6 & 7 & 8 & 9 & 10 \\
\hline \multirow{2}{*}{$\begin{array}{l}\text { 든 } \\
\text { 흔 }\end{array}$} & $\begin{array}{c}\text { SSIM } \\
\text { Value [\%] }\end{array}$ & 32.6 & 27.7 & 20.3 & 19.8 & 16.9 & 13.3 & 20.7 & 29.1 & 41.7 & 48.2 \\
\hline & $\begin{array}{l}\text { Time after } \\
\text { cooling [s] }\end{array}$ & 0.02 & -0.68 & -0.7 & 0.08 & -0.88 & 0.64 & 0.8 & -0.62 & -0.04 & -0.06 \\
\hline \multirow{2}{*}{ 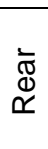 } & $\begin{array}{c}\text { SSIM } \\
\text { Value [\%] }\end{array}$ & 23.1 & 20.8 & 18.0 & 16.4 & 15.2 & 19.4 & 26.2 & 31.2 & 40.4 & 48.6 \\
\hline & $\begin{array}{l}\text { Time after } \\
\text { cooling [s] }\end{array}$ & -0.8 & -0.4 & -0.68 & -0.44 & -0.44 & -0.7 & -0.6 & 0.1 & -0.24 & 0.12 \\
\hline
\end{tabular}

\begin{tabular}{|c|c|c|c|c|c|c|c|c|c|c|c|}
\hline \multirow{2}{*}{\multicolumn{2}{|c|}{$\begin{array}{c}\text { WT type } \\
\text { Order }\end{array}$}} & \multicolumn{7}{|c|}{ Quincunx } & \multicolumn{3}{|c|}{ Haar } \\
\hline & & 11 & 12 & 13 & 14 & 15 & 16 & 17 & 1 & 2 & 3 \\
\hline \multirow{2}{*}{ 这 } & $\begin{array}{c}\text { SSIM } \\
\text { Value [\%] }\end{array}$ & 64.0 & 64.5 & 72.2 & 72.2 & 69 & 66.3 & - & 7.5 & 19.4 & 44.8 \\
\hline & $\begin{array}{l}\text { Time after } \\
\text { cooling [s] }\end{array}$ & -0.04 & 0.02 & 0.08 & 0.08 & 0.14 & 0.98 & - & 2.56 & 0.78 & 1.5 \\
\hline \multirow{2}{*}{ 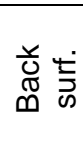 } & $\begin{array}{c}\text { SSIM } \\
\text { Value [\%] }\end{array}$ & 50.6 & 51.7 & 63.2 & 61.0 & 65.2 & - & - & - & 27.5 & 46.9 \\
\hline & $\begin{array}{l}\text { Time after } \\
\text { cooling [s] }\end{array}$ & 0.62 & 0.16 & 0.16 & 0.16 & -0.24 & - & - & - & 3.62 & 2.6 \\
\hline
\end{tabular}

\begin{tabular}{|c|c|c|c|c|c|c|c|c|c|c|}
\hline \multirow{2}{*}{\multicolumn{2}{|c|}{$\begin{array}{c}\text { WT type } \\
\text { Order }\end{array}$}} & \multicolumn{3}{|c|}{ Meyer } & \multicolumn{3}{|c|}{ Symlets 1} & \multicolumn{3}{|c|}{ Symlets 2} \\
\hline & & 1 & 2 & 3 & 1 & 2 & 3 & 1 & 2 & 3 \\
\hline 亡े 0 & $\begin{array}{c}\text { SSIM } \\
\text { Value [\%] }\end{array}$ & 5.1 & 8.9 & 18.8 & 7.5 & 19.4 & 44.8 & 8.1 & 20.1 & 37.0 \\
\hline
\end{tabular}


10.21611/qirt.2018.p26

$14^{\text {th }}$ Quantitative InfraRed Thermography Conference, 25 - 29 June 2018, Berlin, Germany

\begin{tabular}{|c|c|c|c|c|c|c|c|c|c|c|}
\hline & $\begin{array}{l}\text { Time after } \\
\text { cooling [s] }\end{array}$ & 0.96 & 3.2 & -1.0 & 2.56 & 0.78 & 1.5 & 2.02 & 2.9 & 2.6 \\
\hline \multirow{2}{*}{ 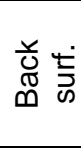 } & $\begin{array}{c}\text { SSIM } \\
\text { Value [\%] }\end{array}$ & 4.1 & - & 23.8 & - & 27.5 & 46.9 & - & 17.9 & 39.6 \\
\hline & $\begin{array}{l}\text { Time after } \\
\text { cooling [s] }\end{array}$ & 0.84 & - & 3.54 & - & 3.62 & 2.6 & - & -1.08 & 3.54 \\
\hline
\end{tabular}

\begin{tabular}{|c|c|c|c|c|c|c|c|c|c|c|}
\hline \multirow{2}{*}{\multicolumn{2}{|c|}{$\frac{\text { WT type }}{\text { Order }}$}} & \multicolumn{3}{|c|}{ Symlets 3} & \multicolumn{3}{|c|}{ Daubechies 2} & \multicolumn{3}{|c|}{ Daubechies 3} \\
\hline & & 1 & 2 & 3 & 1 & 2 & 3 & 1 & 2 & 3 \\
\hline \multirow{2}{*}{ 蒙 吉 } & $\begin{array}{c}\text { SSIM } \\
\text { Value [\%] }\end{array}$ & 8.0 & 18.0 & 31.2 & 8.1 & 20.1 & 37.0 & 8.0 & 18.0 & 31.2 \\
\hline & $\begin{array}{l}\text { Time after } \\
\text { cooling [s] }\end{array}$ & 3.26 & 1.48 & 1.02 & 2.02 & 2.9 & 2.6 & 3.26 & 1.48 & 1.02 \\
\hline \multirow{2}{*}{ 旁 } & $\begin{array}{c}\text { SSIM } \\
\text { Value [\%] }\end{array}$ & 13.8 & 19.9 & - & - & 17.9 & 39.6 & 13.8 & 19.9 & - \\
\hline & $\begin{array}{l}\text { Time after } \\
\text { cooling [s] }\end{array}$ & -1.24 & -1.04 & - & - & -1.08 & 3.54 & -1.24 & -1.04 & - \\
\hline
\end{tabular}

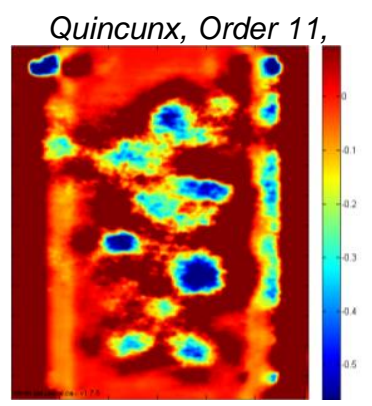

Haar, Order 3

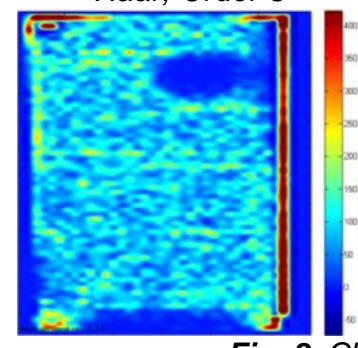

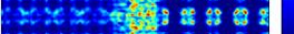

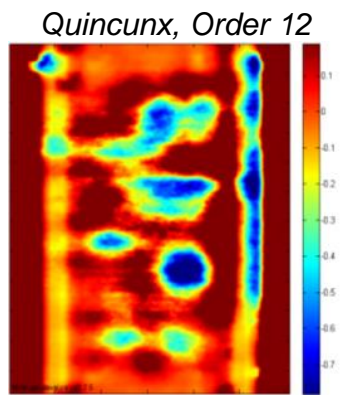

Meyer, Order 3

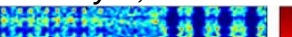

andunt

(x)

Golity
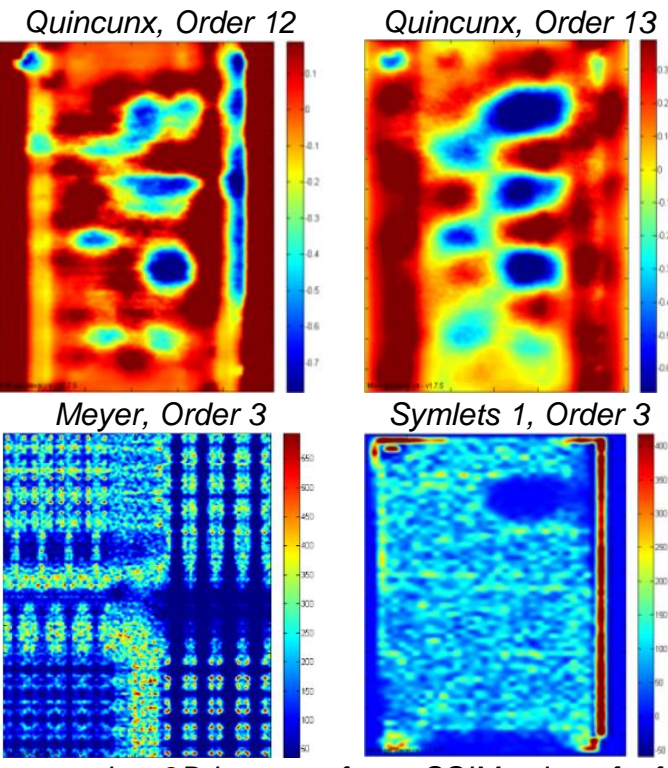

Symlets 1, Order 3
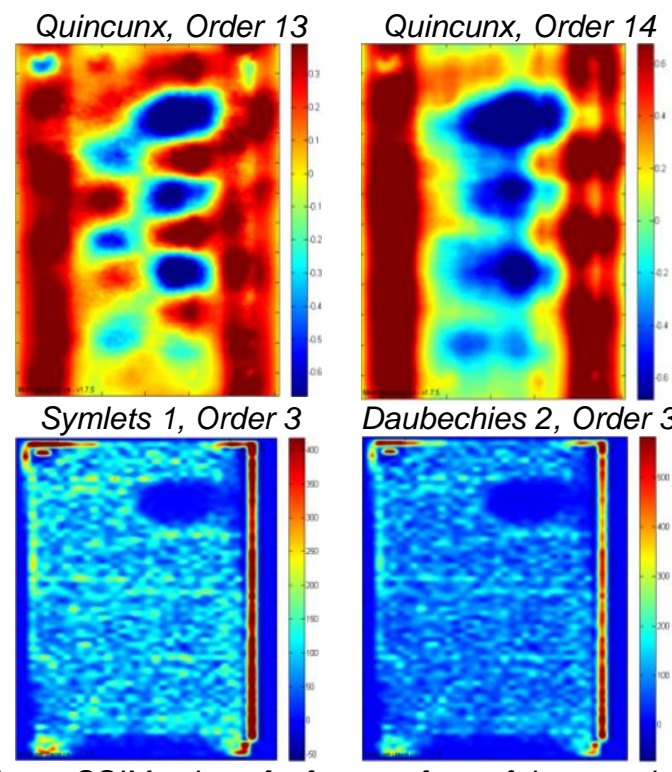

Daubechies 2, Order 3

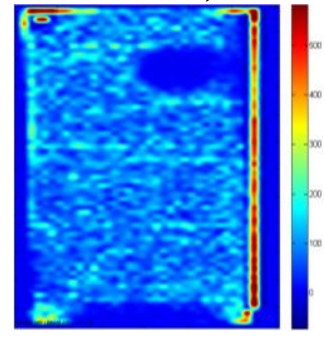

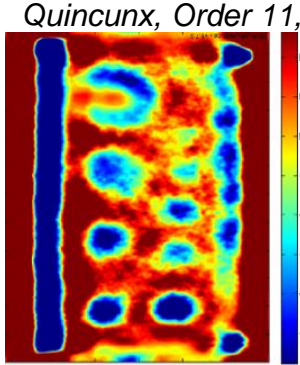

Haar, Order 3

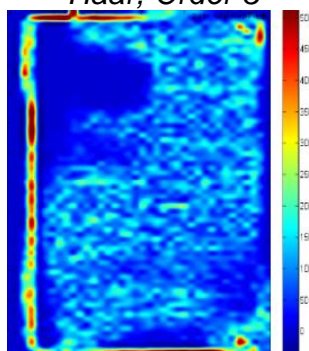

Quincunx, Order 12

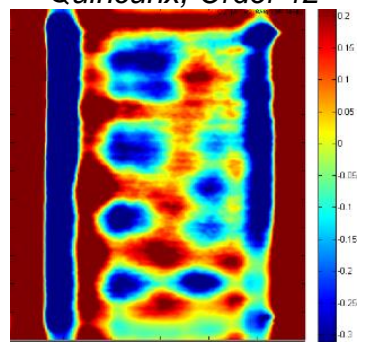

Meyer, Order 3

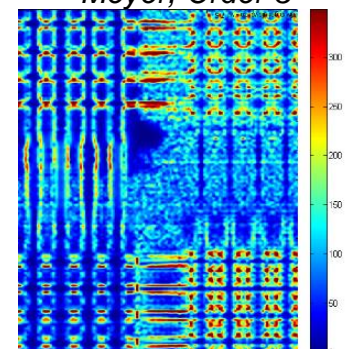

Quincunx, Order 13

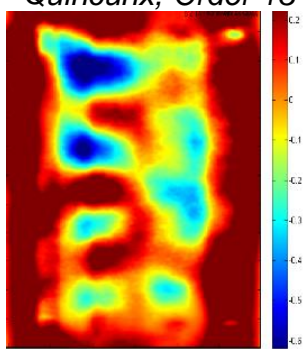

Symlets 1, Order 3

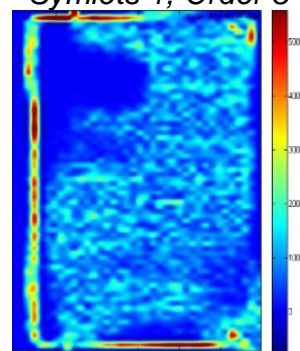

Quincunx, Order 14

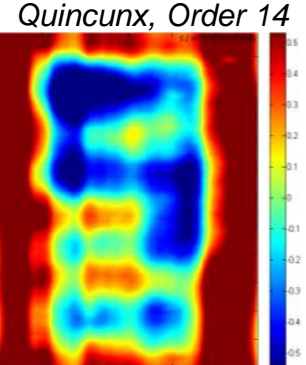

Daubechies 2, Order 3

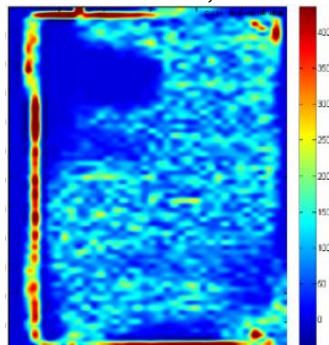

Fig. 9. Chosen wavelets $2 D$ images of max SSIM value of a back surface of the sample 
Analysis of the SSIM values and visual inspection of images indicated that classic wavelets gives worst results than quincunx one. Using SSIM values for the images processed using quincunx wavelet it is possible to find cooling time were the best visibility of defects on raw images should be visible. In Fig 10 and 11 plots of SSIM value as cooling time function were presented for both sides of investigated specimen. Plots shown SSIM for a quincunx wavelet of orders 1114. Moreover, the best visual and SSIM value WT images are presented in Fig 12.

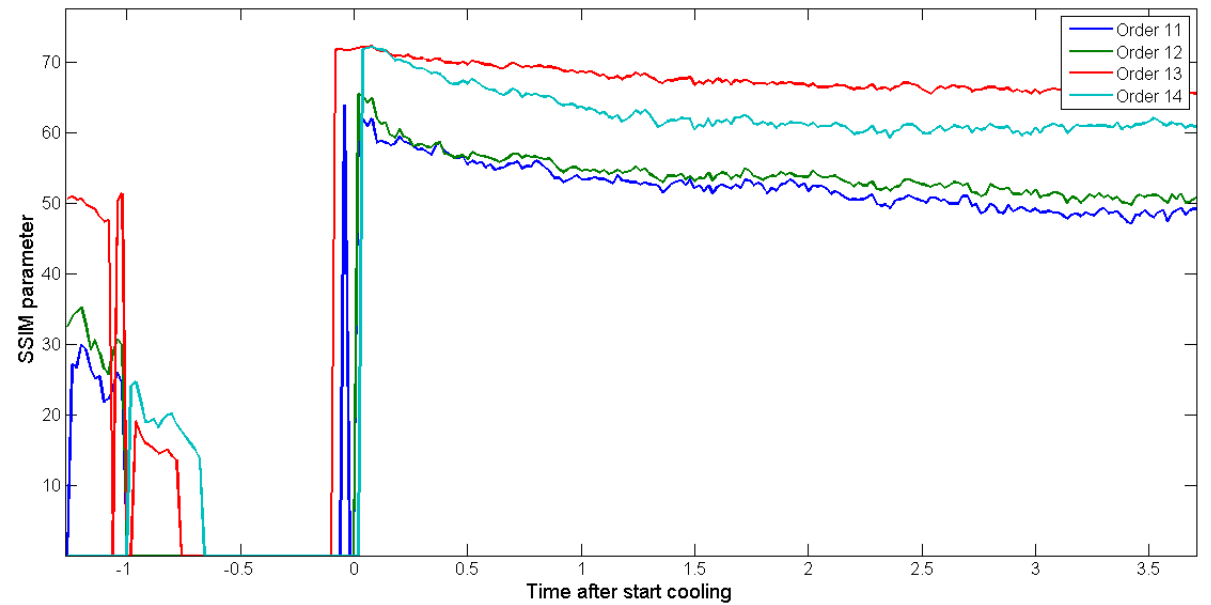

Fig. 10. SSIM parameter changes during the test sequence for quincunx wavelet order from 11 to 14 , for the front surface of the sample.

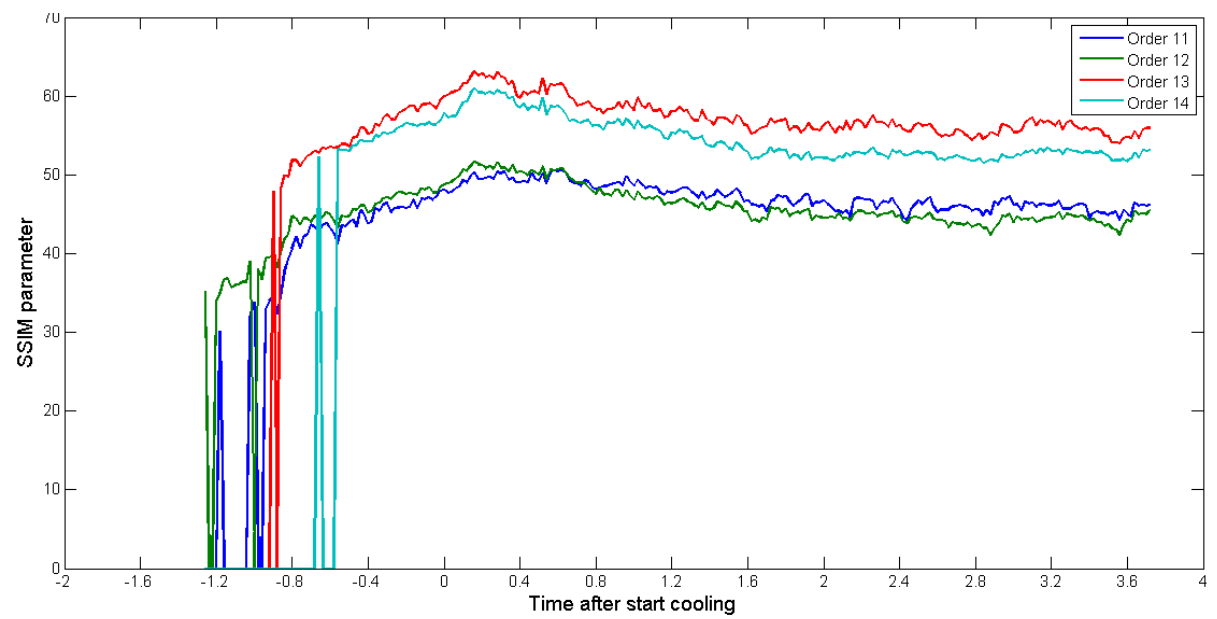

Fig. 11. SSIM parameter changes during the test sequence for quincunx wavelet order from 11 to 14 , for the back surface of the sample.

The best SSIM value (Quincunx, Order 13, Front side)

Raw IR image

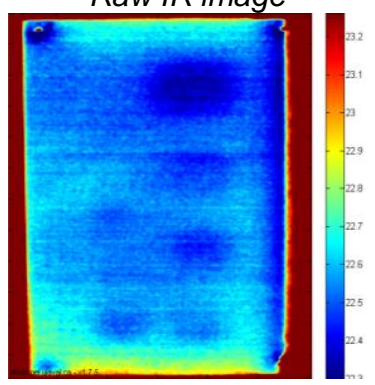

Fig. 12. Image with the highest SSIM value After WT

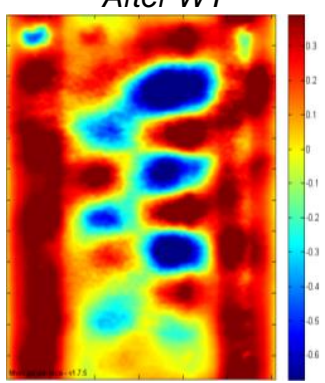

Visually the best image (Quincunx, Order 11, Back side)
Raw IR image

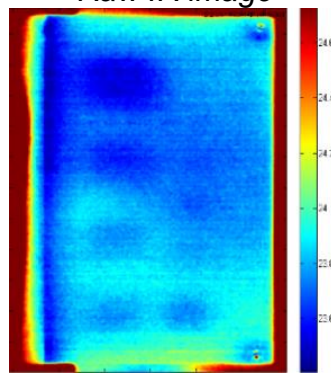

After WT

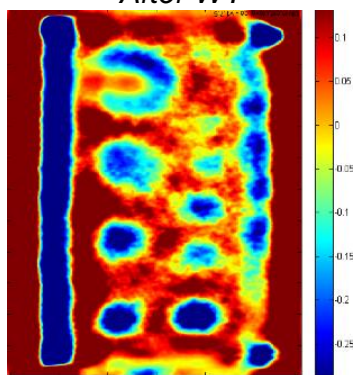
raw IR images 


\section{Conclusions}

The provided investigations and analysis, proofs that 2D wavelets are potentially good processing methods which can improve defect visibility in bonded structures. This situation can be observe on Fig. 12 ( Quincunx, Order 11), where almost every element of adhesive layout (Fig.1a) can be found. Moreover Fig. 10. and 11. gives almost unequivocal information about time of the best results. The presented approach could be used as a tool to decrease number of images which should be compared visually. In this article it was possible to reduce investigation to 16 image from huge data set (20000 images in total) thanks to the SSIM similarity assessment. Additionally, SSIM method is relatively fast. Unfortunately, SSIM value is not precise enough to choose the best, singular result. Probably, some of the other, more complex methods should be used to support the overall assessment method. Quincunx WT is very promising method.

\section{REFERENCES}

[1] Maldague X. P.: Theory and Practice of Infrared Technology for Nondestructive Testing. Wiley. 2001

[2] Shull P. J.: Nondestructive Evaluation. Theory, Techniques and Applications. Marcel Dekker Inc., 2001.

[3] Suszyński Z.: Termografia aktywna: modele, metody pomiaru i przetwarzanie obrazów termograficznych. Koszalin 2013.

[4] Katunin A.: Stone impact damage identification in composite plates using modal data and quincunx wavelet analysis. Archives of Civil and Mechanical Engineering, ISSN: 1644-9665, Vol: 15, Issue: 1, Page: 251-261, 2015.

[5] Wang Z. and Bovik A. C.: "Mean squared error: love it or leave it? - A new look at signal fidelity measures," IEEE Signal Processing Magazine, vol. 26, no. 1, pp. 98-117, Jan. 2009.

[6] Wang, Z.; Simoncelli, E.P.; Bovik, A.C.: Multiscale structural similarity for image quality assessment. Conference Record of the Thirty-Seventh Asilomar Conference on Signals, Systems and Computers, 2004. 2: 1398-1402 Vol.2.

[7] Feilner M., Van De Ville D., Unser M.: An orthogonal family of quincunx wavelets with continuously adjustable order. IEEE Transactions on Image Processing, 14 (4) (2005), pp. 499-510

[8] Kurpiński M., Fidali M.: Detection of Bounded Joint Defects by use of Lock-in Thermography, Measurement Automation Monitoring, vol. 10/2016

[9] Torrence C. and Compo G. P.: A Practical Guide to Wavelet Analysis. Bulletin of the American Meteorological Society. 62, Vol. 79, No. 1, January 1998

[10] Kopeć M., Kałuża M., Więcek B.: Comparison of thermal impedance and wavelets analysis for non-destructive testing. Measurement Automation Monitoring, Jun. 2015, vol. 61, no. 06

[11] Lee D. T.L., Yamamoto A.: Wavelet Analysis: Theory and Applications. Hewlett-Packard Journal, December 1994

[12] Santini, S., Jain, R.: Similarity Measures. IEEE Trans. Patt. Anal. Mach. Intell. 21, 871-883 (1999)

[13] Baudrier, E., Millon, G., Nicolier, F., Ruan, S.: The adaptive local Hausdorff-distance map as a new dissimilarity measure. Patt. Recogn. 41, 1461-1478 (2008) 